\title{
OS/AS ROBÔS TÊM SEXO? UMA ANÁLISE A PARTIR DA CATEGORIA DE GÊNERO A RESPEITO DA REPRESENTAÇÃO DE MULHERES EM MÁQUINAS
}

\author{
Claudete Beise Ulrich* \\ Vinicius Silva de Oliveira**
}

\section{RESUMO}

Os/as robôs estão cada vez mais sofisticados, fazendo parte dos nossos cotidianos, nos diferentes contextos. Essa presença nos faz levantar as seguintes perguntas: será que eles/as têm sexo? Se sim, qual será o sexo: masculino, feminino e/ou outro? O presente texto busca refletir sobre esta questão: se os/as robôs têm sexo e como são representados/as. Objetivamos realizar uma análise da relação do ser humano masculino com a representação máquina/robô feminina a partir da categoria analítica de gênero e da perspectiva da religião. A metodologia utilizada é bibliográfica, além de pesquisa em páginas especializadas sobre desenvolvimento e venda dos/ as sexbots. A pesquisa revela paralelos na representação do papel feminino em máquinas com discursos religiosos, os quais colocam a mulher como subordinada e submissa ao homem. No processo de criação da mulher-máquina, o homem é elevado ao papel de deus e a mulher é posta como um ser em situação de dependência do seu criador masculino. Consideramos que este tema necessita ser refletido

* Doutora em Teologia pelas Faculdades EST. Pós-doutora em História pela UFSC e Pós-doutora em Educação pela UFES. Professora de Teologia na graduação e no Mestrado Profissional em Ciências da Religião da Faculdade Unida Vitória. Coordenadora da Graduação EAD em Ciências das Religiões. Coordenadora do Grupo de Pesquisa "Religião, Gênero, Violências: Direitos Humanos” e Cátedra de Teologia Pública e Estudos da Religião Rev. João Dias de Araújo. E-mail: claudete@fuv.edu.br. Orcid: http://orcid.org/0000-0002-9830-3768

** Mestrando do Programa de Pós-graduação em Ciências das Religiões da Faculdade Unida de Vitória. Bacharel em Teologia pela Faculdade Unida de Vitória. Pesquisador do Grupo de Pesquisa “Religião, Gênero, Violências: Direitos Humanos”. Atua como professor tutor na Licenciatura em Ciências das Religiões. E-mail: vinicius@fuv.edu.br. Orcid: http://orcid.org/oooo-0002-6798-6850 
e aprofundado a partir de uma perspectiva da ética feminista e das ciências das religiões, pois as mulheres continuam sendo coisificadas e submetidas nas relações seres humanos-máquinas.

Palavras-chave: Relações de Gênero. Mulheres-Máquinas. Sexbots. Ética Feminista. Religiões.

\section{DO ROBOTS HAVE SEX? AN ANALYSIS FROM THE GENDER CATEGORY REGARDING WOMEN REPRESENTATION IN MACHINES}

\section{ABSTRACT}

Robots are getting more and more sophisticated, being part of our day-to-day life in different contexts. This presence makes us ask the following questions: do robots have a sex? If so, which sex will it be: male, female and/or other? This text seeks to reflect on this issue: if robots have a sex and how is it represented. We aim to carry out an analysis of the male human relationship with the female machine/ robot representation from the analytical category of gender and the perspective of religion. The methodology used is the bibliographic, in addition to research in specialized pages about the development and sale of sexbots. The research reveals parallels in the representation of the female role in machines with religious speeches that place women as subordinate and submissive to men. In the process of creating a machine-woman, man is elevated to the role of god and the woman is seen as a being placed in a situation of dependence on her male creator. We believe that this topic needs to be reflected and deepened from a feminist ethics and religion sciences perspective, because women continue to be objectified and submitted in the human-machine relationships.

Key words: Gender relations. Machine-women. Sexbots. Feminist ethics. Religion.

\section{¿LOS/AS ROBOTS TIENEN SEXO? ANÁLISIS DE LA CATEGORÍA DE GÉNERO PARA LA REPRESENTACIÓN DE MUJERES EN MÁQUINAS}

\section{RESUMEN}

Los robots se están volviendo cada vez más sofisticados, formando parte de nuestro día a día, en diferentes contextos. Esta presencia nos hace plantear las siguientes preguntas: ¿los robots tienen sexo? Si es así, ¿de qué sexo será: masculino, femenino y/u otro? Este texto 
busca reflexionar sobre este tema: si los robots tienen sexo y cómo se representa. Este texto busca reflexionar sobre este tema: si los robots tienen sexo y cómo son representados. Nuestro objetivo es realizar un análisis de la relación del hombre con la representación máquina/- robot femenina desde la categoría analítica de género y la perspectiva de la religión. La metodología utilizada es la bibliográfica, además de la investigación en páginas especializadas sobre el desarrollo y venta de sexbots. La investigación revela paralelismos en la representación del rol femenino en máquinas con discursos religiosos, que sitúan a las mujeres como subordinadas y sumisas a los hombres. En el proceso de creación de una máquina-mujer, el hombre es elevado al papel de dios y la mujer se ve colocada en una situación de dependencia de su creador masculino. Creemos que este tema necesita ser reflejado y profundizado desde una perspectiva feminista y de las ciencias de la religión, porque las mujeres continúan siendo objetivadas y sometidas en las relaciones hombre-máquina.

Palabras clave: Relaciones de Género.Maquinas-Mujeres. Sexbots. Etica Feminista. Religiones

\section{INTRODUÇÃO}

Os/as robôs estão cada vez mais presentes em nossos cotidianos e em todos os contextos. O que são robôs, qual é a sua finalidade? Robôs são máquinas construídas pelos seres humanos, que buscam colaborar ou diminuir o esforço humano e também auxiliam em casos de doenças. Bem, é assim que imaginamos e pensamos os robôs. Este texto busca responder uma pergunta: Mas será que eles/as têm sexo? Qual sexo: masculino, feminino, outro? Qual a relação que tem sido estabelecida entre os seres humanos e as máquinas/robôs? Esta é uma pergunta que se liga com as relações que também estabelecemos com outros humanos, pois o robô é uma construção humana. A construção de máquinas para fins sexuais também tem se tornado cada vez mais popular.

O presente artigo objetiva realizar uma análise da relação do ser humano masculino com a máquina/robô feminino a partir da categoria analítica gênero, trabalhados por Joan Scott e Judith Butler. Levantamos uma discussão sobre as sexbots, e como esses robôs refletem antigos arquétipos em relação ao papel das mulheres na sociedade ocidental, reafirmando a submissão. A forma como essas máquinas performam o gênero revela antigos alicerces sobre os quais a sociedade ocidental 
cristã está estabelecida, afirmando a desigualdade entre homens e muIheres, apontando para questões éticas que necessitam ser enfrentadas (Dora KAUFMANN, 2016). O artigo está dividido em três partes: Robôs: Inteligência artificial, Categoria analítica de gênero, Sexbot: porque analisar gênero em máquinas e os desafios para uma ética feminista e, nas considerações finais, apontamos para outras questões que necessitam de reflexão na temática que envolve robôs e as representações humanas, especialmente de mulheres, de pessoas de outras etnias, de crianças.

\section{ROBÔS: INTELIGÊNCIA ARTIFICIAL}

O termo robô surge da palavra tcheca robota, que era a designação para trabalho forçado. Seu uso tornou-se popular a partir de 1921 devido à peça teatral R.U.R, sigla para Rossum's Universal Robots, na qual o protagonista, Dr. Rossum, desenvolve uma solução que visa a transformação de órgãos biológicos em partes mecânicas, convertendo seus portadores em obedientes servos. Porém, assim como o monstro de Frankenstein, da autora Mary Shelley, estes rompem com a condição de subserviência e se rebelam contra seus mestres (José Antônio Colvara OLIVEIRA, 2007). Outra forma de descrever robôs seria como entidades criadas artificialmente, inseridas num contexto humano social e de gênero (Roger Andre SøRAA, 2017).

Robôs não precisam ser necessariamente capazes de "pensar", mas os avanços no campo da Inteligência Artificial (IA), possibilitaram o desenvolvimento de diversos estudos e elaboração de teorias, aliadas à busca por compreender o funcionamento da inteligência humana, a fim de desenvolver máquinas que possam imitar a capacidade de processamento de dados do cérebro humano (Yang XIN; Lingshuang KONG; Zhi LIU et al., 2018). As pesquisas e aplicações de IA's vão desde veículos autônomos, reconhecimento de voz, robótica, linguagem neural, serviços de recomendação e etc. Para Dora Kaufman (2016), isso traz certa dificuldade para determinar "estado-da-arte" atual da IA, pois hoje elas podem ser utilizadas para todas as áreas do conhecimento. Essas IAs são softwares e/ou algoritmos que processam dados (informações), aprendem com eles e se tornam capazes de resolver complexos problemas lógicos e tipos de linguagens (Ebba ENGSTROM, 2018). 
Em 2018, a Gartner, uma empresa especializada em consultoria empresarial, elencou as 35 principais tecnologias emergentes previstas para os próximos 10 anos. Dentre as cinco principais figura a democratização da Inteligência Artificial (IA), sendo esta a de maior impacto na sociedade. No mesmo artigo, a Gartner alerta para que as empresas estejam atentas para o papel fundamental do uso das IA's para a sobrevivência de seus negócios (Conn STAMFORD, 2018). Diante desse crescimento significativo da presença da IA, associada à Robótica, Takeshi Kimura destaca a relevância e necessidade de investigar a relação humano/a-religião-tecnologia e as novas representações que se originam dessa relação. Kimura também aponta que dia após dia as fronteiras entre humanos/as e máquinas estão se fluidificando, sendo possível encontrar tanto elementos tecnológicos, ditos seculares, na religião quanto a influência de certos elementos religiosos sobre o significado dessas tecnologias emergentes (Takeshi KIMURA, 2017). Neste sentido, é necessário considerar que o avanço da IA terá influência na vida cotidiana, nas relações sociais, de gênero, de trabalho, entre outras.

Observamos que a concepção e uso que se dá às máquinas, IA s e robôs recebe influência ativa de modelos patriarcais, brancos e coloniais, oriundos de contextos sociorreligiosos tradicionais e conservadores no que se refere ao trato com as mulheres. De maneira bem similar à forma como as mulheres são tratadas em alguns grupos religiosos cristãos, máquinas são designadas para a performance de papeis tidos como femininos, sendo colocadas em posição de serviço ou de subordinação. Alguns grupos religiosos cristãos afirmam que é da "vontade de Deus" a presença de uma figura de autoridade masculina e que as mulheres sejam colocadas em posições de subordinação a esta. Interessante perceber que, no novo modelo de relação humano-tecnologia, o homem passa atuar como "deus" e, por meio da autoridade do programador, essas máquinas designadas feminilizadas passam a performar em papel de submissão. É sabido que a religião tem papel gerador de sentido, tanto para o bem quanto para o mal. Sandra Duarte de Souza (2004) amplia o conceito de religião, apontando para a mesma como

uma construção sócio-histórico-cultural. Portanto, discutir religião é discutir transformações sociais, relações de poder, de classe, de 
gênero, de raça/etnia; é adentrar num complexo sistema de trocas simbólicas, de jogos de interesse, na dinâmica da oferta e da procura; é deparar-se com um sistema sócio-cultural permanentemente redesenhado que permanentemente redesenha as sociedades. (Sandra Duarte de SOUZA, 2004, p. 122)

A religião está ligada com um complexo sistema sociocultural, que também inclui a tecnologia, redesenhando relações de gênero. Como já apontamos anteriormente, uma parte considerável das culturas ocidentais cristãs considera que o feminino é "destinado" à subserviência e, para além disso, as mulheres são vistas como agentes do mal e da desordem. Esta posição de promotora do caos justificou a exclusão da presença de mulheres dos espaços de poder e de tomada de decisão, invisibilizando e silenciando essas mulheres (Haidi JARSCHEL; Cecília Castilho NANJARÍ, 2008; Maria José ROSADO, 2001):

A religião e cultura estão intricadas em sua forma de manifestação na sociedade e na vida das pessoas. As crenças religiosas entram na construção cultural formando um todo sistêmico, difícil de separar mesmo num Estado Laico, onde há uma clara divisão entre Estado e religião. É possível separá-las apenas para análise, mas no cotidiano das pessoas ela exerce uma influência indissociável. Sobre a base da vivência humana, em suas fibras mais intimas, se inserta a experiência religiosa. Está inserida na experiência geral, pode ser distinguida, mas não separada. O que é variável é a relação com o sagrado ou o mistério. É sempre uma vivência relacional (outros/mundo) com o transcendente, no entanto sempre é uma experiência humana (Haidi JARSCHEL; Cecília Castilho NANJARí, 2008, p. 4).

As mulheres não apenas tiveram seus lugares cooptados na esfera pública como reflexo da religião, mas também seus corpos e sua sexualidade. Ivone Gebara, em entrevista à Revista Estudos Feministas, afirma que o corpo feminino foi e é submetido à violência, à opressão e à dominação de gênero. Nessa perspectiva opressora surge a dominação do feminino pelo masculino (Maria José ROSADO-NUNES, 2006). Essa dominação é elevada a um novo patamar com a entrada dos/das sexybots, onde o corpo feminino é totalmente apagado nas relações afetivas e sexuais, onde esses homens, como veremos na terceira seção desse artigo, encontram 
em máquinas para uso sexual a "reparação" desse mal primordial que o corpo da mulher representa dentro da camada sociorreligiosa. Essas robôs são construídas com o único propósito de serem o símbolo máximo da dominação sexual por parte dos homens, herdeiros da experiência religiosa patriarcal (David LE BRETON, 2013). O gênero feminino em robôs é uma representação máxima da negação das mulheres, pois representam a mulher silenciada, privada de sentimentos próprios, de vontades e do prazer sexual, sujeitas exclusivamente à vontade dos homens.

Neste artigo, buscamos refletir a partir da categoria analítica de gênero sobre a representação de mulheres em máquinas (sexbot) e como as mesmas são utilizadas pelos homens. Antes de elencar algumas representações de mulheres em máquinas, seguem algumas reflexões sobre gênero como categoria de análise.

\section{CATEGORIA ANALÍTICA DE GÊNERO}

A motivação de Joan Wallach Scott para teorizar sobre gênero "era e é compartilhada com outras feministas e é abertamente política: apontar e modificar as desigualdades entre homens e mulheres" (Joan Wallach SCOTT, 1994, p. 14). Ela pretendeu propor uma análise sobre "como as hierarquias de gênero são construídas, legitimadas, contestadas e mantidas" (Joan Wallach SCOTT, 1994, p. 14), vencendo, dessa forma, o determinismo biológico que afirma: assim é uma mulher e assim é um homem. Há múltiplas formas de ser mulher e de ser homem. O uso da categoria de análise de gênero permite que se focalize e reflita sobre as relações entre homens e mulheres, mas também sobre as relações entre homens e homens e entre mulheres e mulheres (Claudete Beise ULRICH, 2013). Segundo Joan Wallach Scott, o gênero:

[...] tem duas partes e várias sub-partes. Elas são ligadas entre si, mas deveriam ser analiticamente distintas. O núcleo essencial da definição baseia-se na conexão integral entre duas proposições: o gênero é um elemento constitutivo de relações sociais baseado nas diferenças percebidas entre os sexos, e o gênero é uma forma primeira de significar as relações de poder. As mudanças na organização das relações sociais correspondem sempre à mudança nas representações de poder, mas a direção da mudança não segue necessariamente um sentido único (1990. p. 14). 
A autora citada, no entanto, chama a atenção para a necessidade de extrapolar o uso descritivo do gênero, entendendo e demonstrando os mecanismos pelos quais o gênero opera em vários campos da vida em diferentes tempos. É necessário articular gênero como categoria analítica, "um meio de decodificar o sentido e de compreender as relações complexas entre diversas formas de interação humana" (Joan Wallach SCOTT, 1990, p. 7-8) e o "gênero é uma forma primeira de significar as relações de poder" (Joan Wallach SCOTT, 1990, p. 14). Neste sentido, ainda segundo a autora, gênero implica em quatro elementos relacionados entre si:

[...] primeiro - símbolos culturalmente disponíveis que evocam representações múltiplas (freqüentemente contraditórias) - Eva e Maria, como símbolo da mulher, por exemplo, na tradição cristão do Ocidente, mas também mitos da luz e da escuridão, da purificação e da poluição, da inocência e da corrupção. Para os(as) historiadores(as), as questões interessantes são: quais as representações simbólicas evocadas, quais suas modalidades, em que contextos?

[...] Segundo - conceitos normativos que colocam em evidência interpretações do sentido dos símbolos que tentam limitar e conter as suas possibilidades metafóricas. Esses conceitos são expressos nas doutrinas religiosas, educativas, científicas, políticas ou jurídicas e tipicamente tomam a forma de uma oposição binária que afirma de forma categórica e sem equívoco o sentido do masculino e do feminino. [...] Um outro exemplo vem dos grupos religiosos fundamentalistas de hoje que querem necessariamente ligar as suas práticas à restauração do papel "tradicional" das mulheres, supostamente mais autêntico, enquanto que na realidade tem poucos antecedentes históricos que testemunhariam a realização inconteste de um tal papel. O objetivo da nova pesquisa histórica é explodir a noção de fixidade, descobrir a natureza do debate ou da repressão que leva a aparência de uma permanência eterna na representação binária dos gêneros. Esse tipo de análise tem que incluir uma noção do político, tanto quanto uma referência às instituições e organizações sociais. Esse é o terceiro aspecto das relações de gênero.

O quarto aspecto do gênero é a identidade subjetiva. Conferências estabelecem distribuições de poder (um controle ou um acesso diferencial aos recursos materiais e simbólicos), o gênero torna-se implicado na concepção e na construção do poder em si (Joan Wallach SCOTT, 1990, p. 14-15). 
O gênero como categoria de análise necessita perceber os símbolos e os conceitos normativos que são expressos nas doutrinas religiosas, nas organizações sociais, mas também nas mídias sociais, nas novas tecnologias e como estes formam o gênero, (re) afirmando uma posição binária e hierárquica entre o masculino e o feminino. "O conceito de gênero serve, assim, como uma ferramenta analítica que é, ao mesmo tempo, uma ferramenta política" (Joan Wallach SCOTT, 1990, p. 16), tendo um caráter relacional (Guacira Lopes LOURO, 1997), e aponta para uma identidade subjetiva que não é fixa. Constatamos que há uma diversidade de gêneros que coexistem em cada sociedade, em cada comunidade e em cada pessoa. É possível que uma pessoa, ao longo de sua vida, modifique a sua visão de gênero, devido às transformações em sua própria pessoa e na sociedade, apresentando mudança de valores, normas e maneiras de entender a si mesma e aos outros indivíduos. Portanto, "certas atitudes não são naturais do ser humano, mas foram construídas no decorrer dos processos históricos, fortalecendo um jeito cultural de ser" (Claudete ULRICH, 2013).

Neste sentido, Judith BUTLER (1990) aponta para a performatividade de gênero. Segundo a autora, as identidades de gênero são performaticamente constituídas, em ato aberto a cisões, sujeito a paródias, autocríticas e exibições hiperbólicas do natural. Segundo Judith Butler,

Se o gênero são os significados culturais assumidos pelo corpo sexuado, não se pode dizer que ele decorra, de um sexo desta ou daquela maneira. Levada a seu limite lógico, a distinção sexo/gênero sugere uma descontinuidade radical entre corpos sexuados e gêneros culturalmente construídos. (Judith BUTLER, 1990, p. 24)

Segundo Judith BUTLER, "a performatividade não é, assim, um ato singular, pois ela é sempre uma reiteração de uma norma ou conjunto de normas" (2001, p. 167). A autora comenta que a repetição de certos gestos como comportamento de gênero, reitera os corpos sexuados e estruturas e cristaliza a regularização destes corpos como uma substância ou classe natural de ser. Nos corpos se reproduzem mundos ou se rompe com mundos. Neste sentido, as diferentes formas dos corpos se colocarem nas diferentes sociedades rompem com modelos mascu- 
linos e femininos colocados como verdades únicas. Há diversidade e pluralidade nos corpos.

O corpo é exposto como uma chave hermenêutica, uma questão epistemológica importante para repensar a relação com a sociedade, com a religião, com o conhecimento. O corpo não pertence somente ao mundo privado, mas sim ao mundo público. Por isto, em briga de marido e mulher se mete a colher sim, e se busca romper com o círculo da violência doméstica. Procuramos romper também com a heteronormatividade/heterossexualidade ${ }^{1}$ como norma única para a sociedade. Gênero, portanto, é uma categoria importante também para analisar a relação dos homens com as representações de mulheres em máquinas. Homens "deuses" criam mulheres e reproduzem o sistema patriarcal ocidental cristão.

\section{SEXBOT: POR QUE ANALISAR GÊNERO EM MÁQUINAS E OS DE- SAFIOS PARA UMA ÉTICA FEMINISTA}

A fórmula da mulher "perfeita" não é nova, na realidade são ecos de arquétipos e narrativas que descrevem a visão do ideal de mundo ou a ser perseguido. Em muitas dessas narrativas, a mulher é colocada no centro, como a pivô que estremece as estruturas patriarcais de seu tempo. Medusa transformando seus inimigos, em geral heróis mitológicos, em pedra; a Esfinge egípcia que devorava os viajantes que eram incapazes de responder às suas charadas; Circe que encantava seus visitantes com sua beleza e comida, transformando-os em animais desprovidos de humanidade; as sereias que encantavam os navegantes com belas canções para arrastá-los às profundezas dos mares. A imagem de mulheres fortes, sensuais e inteligentes sempre foi associada a jornadas perigosas e de fins trágicos (Andrea Abalia MARIJUÁN, 2018).

Dentro desse complexo jogo simbólico dos mitos se destaca um, o de Pigmalião e Galateia, no qual é apresentada a figura da mulher fabricada. A história narra a paixão entre um homem e sua mulher de

Judith BUTLER, 1990, p. 176. "A heterossexualidade apresenta posições sexuais normativas que são intrinsecamente impossíveis de incorporar, e a impossibilidade persistente do identificar-se plenamente e sem incoerências com essas posições a revela não só como lei compulsória, mas como comédia inevitável." 
marfim, modelada a partir de seus desejos, livre das inconstâncias das relações humanas e da ação do tempo, um reflexo narcísico de si que nega a alteridade do outro feminino (David LE BRETON, 2013). SemeIhantemente à Virgem Maria, que se apresenta pura, o perfeito inverso proporcional a Eva que se perde em sua corrupção carnal, esse ideal de mulher se estende a todo o imaginário ocidental, até a atualidade. Uma mulher esvaziada de seus desejos, não pensante, com seu corpo convertido em um instrumento a ser dominado (Andrea Abalia MARIJUÁN, 2018, p. 40). Galateia, Maria e diversas outras mulheres castas e santas das histórias do mundo ocidental, têm o seu corpo e pensamento negados pelo homem dominante. Essas narrativas revelam a presença de ódio ao corpo feminino, demonização da mulher carnal e louvor à sua submissão plena (David LE BRETON, 2013).

O pensamento cristão ocidental representa a mulher não como alguém criada à imagem de Deus, mas sim da costela de Adão. Ela é colocada como dependente, frágil, sem capacidade de tomar as próprias decisões, que precisa ser orientada, ensinada e vigiada por uma figura masculina. Se o homem não estiver por perto, dentro de uma perspectiva cristã-patriarcal, novas Evas surgirão para trazer o caos ao mundo. O modelo ideal de mulher para o ocidente cristão é a mulher submissa e de apetite sexual nulo, mas que está sempre disposta a dizer sim à figura masculina de autoridade, seja esta de um homem ou de Deus (Haidi JARSCHEL; Cecília Castilho NANJARí, 2008).

A sexualidade da mulher é arrancada de seu corpo [...] Em poucas palavras, a sexualidade e o erotismo não são sagrados. O corpo sagrado é assexuado, tudo se resume ao ventre. A tradição cristã tem grandes problemas com o corpo e a sexualidade, negando-o da esfera do sagrado. Na corporificação simbólica de Eva como pecadora e Maria como redentora através da submissão e virgindade, está o "bastão do patriarcado" na mão de Deus-Pai que pune e redime. Este bastão está voltado especialmente para a dimensão erótica nas mulheres (Haidi JARSCHEL; Cecília Castilho NANJARÍ, 2008, p. 4).

Ao refletir sobre questões de gênero atribuídas às novas tecnologias, sejam robôs ou IA's ou a junção dos dois, é possível notar ecos da figura de Galateia e Maria: mesmo não possuindo sexo biológico e 
muito menos desenvolvendo por si mesmas características atribuídas ao sexo feminino, nota-se o quanto o seu gênero, decorrente apenas de uma linha de sua programação (que pode determinar o tipo de voz ou a qualquer aparato físico que o distingue), é definido pelo ideário da heteronormatividade. O gênero em robôs é, por excelência, uma construção, uma performance, derivada da ideia daqueles/as que os/ as desenvolvem, na maioria das vezes homens/hetero/brancos, tal qual o sujeito universal citado por Buttler (1990). Eles se comportam como influencers na concepção e no impacto gerado ao atribuir características e funções a um robô, em base às suas próprias concepções de gênero (Ebba ENGSTROM, 2018)

Uma pesquisa realizada em 2009 apontou que robôs ditos femininos, usados por associações de caridade, possuíam maior apelo para a arrecadação de doações, se comparados a robôs masculinos (Mikey SIEGEL; BREAZEAL, Cynthia BREAZEAL e Michael I. NORTO, 2009). Roger Andre SØRAA (2017) aponta que, até 2010, a maioria das pesquisas sobre robótica que observava o gênero dos participantes, tinha como foco a maneira como homens e mulheres interagiam com as máquinas, sem levar em consideração o gênero da máquina, mesmo sendo o gênero uma característica humana que na maioria dos casos define a forma como os/as humanos/as se relacionam com o/a outro/a.

Em seu trabalho Roger Andre SøRAA (2017) põe lado a lado as ideias de Donna HARAWAY (1994) e Jennifer ROBERTSON² (2018), sendo que a primeira defende a ideia de que ciborgue, como produto do encontro entre humano e máquina, seria protagonista da ruptura final com o ideal heteronormativo, enquanto a segunda argumenta que androides e ginoides, entidades mecânicas que simulam o humano, são vítimas de um sexismo pós-humano, pois lhes são atribuídos gêneros e papeis a serem executados, muitas vezes relacionados ao lugares heternormativos/ patriarcais que lhes são impostos, tanto por quem os/as desenvolveu, quanto por seus/suas usuários/as (Roger Andre SØRAA, 2017)

O exemplo mais extremo do impacto heteronormativo sobre essas tecnologias são as IA's denominadas sexbot. Em geral são IA's, desenvolvidas para estabelecer relações íntimas entre humanos e máquinas.

É necessário considerar que a autora realizou a sua pesquisa no Japão. 
A manifestação física dessa IA's é mediada por modelos de silicone, na maioria das vezes femininos, desenhados de acordo com o critério e desejo do seu proprietário (Robin MACKENZIE (2014). A interação entre humano e IA pode ser via aplicativos de celular, como o Realdoll ${ }^{X}$, que realiza sua campanha de marketing com base na ideia de que o proprietário possuiria a "companheira perfeita na palma da mão", pois ele poderá personalizar o avatar digital com as características físicas que desejar e alimentar a IA com informações para que ela desenvolva uma determinada personalidade. Elas são vendidas como uma leal amiga, prometendo um jogo de sedução entre humano e máquina que resultará numa retribuição de "amor" por parte da IA, além da possibilidade de contar com múltiplas parceiras com personalidades totalmente diferentes. Tudo isso por apenas US\$29,90 por ano (REALDOLL $\left.{ }^{x}, 2019\right)$ ).

A responsável pela produção do avatar físico das sexbots, Realdoll ${ }^{x}$, é a empresa de robótica Realbotix, que se denomina como uma companhia de pesquisa em alta tecnologia e de produção das mais recentes IA's e de robôs que irão construir o futuro (REALBOTIX, 2019). Eles são os responsáveis pela Harmony, a sexbot que é incorporada à IA Realdoll ${ }^{x}$. Ela é uma cabeça robótica com diversos pontos de articulação no rosto, o que promove a interação com o humano em conversas, com movimento no pescoço, pálpebras e expressões (REALDOLL, 2019). Outra companhia que oferece um produto similar é a LumiDoll, que além de vender as sexbots, possui uma rede de estabelecimentos nos quais o interessado pode apenas alugar um quarto e realizar todas as suas fantasias com essas máquinas (LUMIDOLLS, 2019).

Ao olhar para esses exemplos, fica claro que, como afirma Judith BUTLER (1990), gênero e sexo são produtos de uma construção que é manifesta por meio da relação performativa com o corpo e da visão do leitor universal-hetero-masculino-branco, que irá determinar o gênero e as características físicas ideais para a satisfação de seu desejo, a partir dessa repetição/reprodução no virtual, ou no silicone, daquilo que muitas vezes não o é no mundo biológico. Joan Wallach SCOTT nos faz refletir sobre como as relações de poder se reproduzem na relação seres humanos e máquinas, afirmando relações de poder e controle.

Importante lembrar que, mesmo que ontologicamente máquinas 
e IA's não possuam qualquer gênero ou sexo biológico, eles são criações humanas que refletem os desejos conscientes e inconscientes de seus criadores, que não criam uma sexbot ou robô feminino, mas sim, impõem à máquina o que ela/ele deve ser (Roger Andre SØRAA, 2017). $\mathrm{Na}$ realidade não passam de uma versão caricata das relações de poder vigentes e de imposição de dominação, violenta e heteronormativa. As sexbots são uma representação exacerbada da figura feminina como propriedade do masculino, é a capitalização do símbolo feminino, se antes o pai transferia sua autoridade e direitos de propriedade para o marido, agora qualquer homem pode comprar esse direito com apenas um clique (Haidi JARSCHEL; Cecília Castilho NANJARí, 2008).

Consideramos que é necessário refletir e aprofundar esse tema a partir de princípios éticos feministas, pois as mulheres continuam sendo coisificadas, inferiorizadas e subjugadas através das representações de gênero em máquinas. A tecnologia reproduz o sistema binário de poder, projetando a mulher como aquela que serve como objeto do desejo ou que cuida da casa, do marido, dos filhos, dos idosos. É necessário, portanto, trazer este debate para o cotidiano nas escolas e nas universidades, afirmando a igualdade de gênero, denunciando todos os tipos de opressão, desigualdades, violências. A discussão ética feminista aponta para a necessidade de questionar a forma como é construído o gênero nas máquinas/robôs e como as mesmas reproduzem as mesmas relações hierárquicas de poder, fortalecendo relações de violência. A tecnologia necessita estar atenta ao gênero e construir também na relação seres humanos-máquinas representações que fortalecem e empoderam as mulheres no enfrentamento às violências e em suas lutas por direitos de igualdade e justiça social.

\section{CONSIDERAÇÕES FINAIS}

A tecnologia é parte importante e cada vez mais presente da vida humana, na qual cada vez mais as máquinas e programas têm sido utilizados para facilitar as tarefas cotidianas. Contudo é necessário refletir, a partir das mais variadas perspectivas, sobre diversas questões que permeiam esse cenário híbrido-biológico, a fim de compreender o impacto dessas tecnologias e artefatos tecnológicos sobre as relações 
ser humano-máquina, e como essas relações podem reforçar/atualizar papeis e relações de poder já existentes, e questionáveis, na sociedade.

É fundamental ter em mente que, epistemologicamente, a ideia de robô já aponta para um sujeito mecanizado, vazio de sentido que está submisso/a um/a mestre/a e que, mesmo hoje, máquinas consideradas "inteligentes", têm a capacidade de resolução de problemas medida por sua eficiência na função que exerce, sendo logo substituída por uma versão mais "recente, mais eficiente e sem erros" quando não mais atende a necessidade do usuário. A partir do momento em que essas máquinas assumem, por imposição de sua programação, algum papel de gênero, e esse sujeito mecânico representa um papel de subserviência ao seu mestre, reforça antigas relações de poder entre homens e mulheres.

Nos mitos e nas religiões, a presença de uma representação da mulher perfeita, formada a partir do desejo de seu criador e mestre, na qual o seu corpo e desejo não pertence mais a ela, e sim a seu senhor, a exemplo de Galateia e Maria, demonstra que o desejo e a mentalidade patriarcal se articulam para silenciar o sexo feminino, negando-lhe seu corpo e demonizando sua inteligência e independência. Veja-se Medusa e Esfinge, duas mulheres descritas como criaturas monstruosas que desafiam os padrões de vulnerabilidade desejado, o destino delas é a solidão e a morte. É esse arquétipo subserviente que tem sido reproduzido nas interfaces virtuais, nas quais o público ocidental se sente mais à vontade em ser servido por uma representação feminina do que masculina. A imposição de gênero e de papeis de submissão às máquinas torna-se um reflexo da imaginário ocidental-cristão-patriarcal que ainda permeiam as relações entre homens e mulheres, sendo as máquinas que performam como mulheres passam a ser a representação máxima da violência que mulheres biológicas ainda hoje sofrem.

Por esse motivo é fundamental contemplar gênero como categoria de análise da tecnologia, para que a partir de uma crítica feminista se possa questionar as velhas relações reproduzidas em novas tecnologias. Assim como Scott $(1990,1994)$ sugere, é preciso refletir sobre as relações já pré-existentes mulher-homem, mulher-mulher e homem-homem, para garantir que na relação ser humano-máquina, velhos hábitos ocidentais de inferiorização da mulher não venham a ser reproduzidos, 
superando assim essa visão fundamentada por um rígido determinismo biológico que impõe desde outrora, determinados lugares e funções ao sexo feminino. Abre-se a mão, assim, de certos símbolos socioculturais vigentes, dando espaço a novas perspectivas.

É de vital importância questionarmos os lugares que as máquinas estão ocupando, principalmente ao nos depararmos com a indústria dos sexbots que, em sua performance de gênero, atuam como mulheres totalmente despersonificadas e alienadas de suas versões biológicas. Assim como Galateia, são apenas um reflexo narcisista do seu proprietário, para quem deve se tornar a mulher perfeita, que se comporta apenas como um objeto de prazer sexual unilateral e que, assim como qualquer outra máquina, poderá ser substituída pela versão mais atual e eficiente.

Outra discussão que se abre é a pergunta que envolve as relações étnico-raciais: como as máquinas representam mulheres brancas, negras ou indígenas? Será que os lugares e os serviços atribuídos às mulheres variam de acordo com a sua etnia e a cor da pele? E mais, qual a razão de atribuir gênero a máquinas? Será que máquinas realmente precisam ter gênero ou esse é apenas algum capricho dos seus criadores? Quanto ao futuro do sexo? Quais os limites do sexo com as máquinas? Por exemplo, homens que mantém relações sexuais com sexbot que performam como crianças, pode ser considerado abuso sexual infantil?

Algo comum nas narrativas modernas ocidentais sobre robôs inteligentes é que estes sempre se voltam contra seu mestre, saindo de seu lugar de servidão e se direcionando para o lugar de protagonismo, sejam mulheres robôs, mulheres biológicas e/ou mulheres híbridas. No entanto, é necessário efetuar a crítica às representações tecnológicas a partir da ética feminista, incluindo categorias de análise como sexo, gênero, raça, etnia, religião para que haja um real rompimento com representações produzidos por uma sociedade ditada pelo patriarcado, que se firma em discursos e práticas religiosas misóginas e machistas, que sustentam o poder masculino, submetendo as mulheres às violências e desigualdades de gênero. 


\section{REFERÊNCIAS}

BUTLER, Judith. Corpos que Pesam: sobre os limites discursivos do sexo. Tradução de Tomaz Tadeu da Silva. In: LOURO, Guacira Lopes (Org.). O Corpo Educado: pedagogias da sexualidade. Belo Horizonte: Autêntica, 2001. p. 151-172.

BUTLER, Judith. Problemas de gênero: feminismo e subversão da identidade. Rio de Janeiro: Civilização Brasileira, 1990.

ENGSTROM, Ebba. Gendering of Al/Robots: Implications for Gender Equality amongst Youth Generations. In: NOVA, Eugenia; KAPOTE, Siddhesh; ENGSTROM, Ebba; ALVAREZ, Jose; SONAM, Smriti. Unctad Youth Forum/world Investment Forum. Geneva: Ariel Foundation International, 2018. p. 13-23. p. 14. Disponível em: <https://arielfoundation. org/wp-content/uploads/2019/01/AFI-Changemakers-and-UNCTAD-Delegates-Report-on-Technology-2019.pdf\#page=13>. Acesso em: 15 fev. 2021.

HARAWAY, Donna. Um Manifesto para os Cyborgs: Ciência, Tecnologia e Feminismo Socialista na Década de 80. In: Heloisa Buarque de Hollanda (Org.). Tendências e Impasses: o feminismo como crítica da cultura. Rio de Janeiro: Rocco, 1994. p. 243-287.

JARSCHEL, Haidi Jarschel; NANJARÍ, Cecília Castillo Nanjarí. Religião e violência simbólica contra as mulheres. Fazendo Gênero, Florianopólis, p. 1-8, 2008. Disponível em: < http://www.wwc2017.eventos.dype.com.br/fg8/sts/ST62/Jarschel-Nanjari_62.pdf>. Acesso em: 28 mai. 2021.

KAUFMAN, Dora. Inteligência artificial: questões éticas a serem enfrentadas. In: SIMPÓSIO NACIONAL ABCiber. São Paulo: PUC, 2016, p. 1-16. Disponível em: <http://abciber. org.br/anaiseletronicos/wp-content/uploads/2016/trabalhos/inteligencia_artificial_questoes_eticas_a_serem_enfrentadas_dora_kaufman.pdf>. Acesso em: 15 fev. 2021.

KIMURA, Takeshi. Robotics and Al in the sociology of religion: a human imago roboticea. Social Compass, v. 64, n. 1, jan. 2017, p. 3-22. Disponível em: <https://journals.sagepub. com/doi/10.1177/0037768616683326>. Acesso em: 05 fev. 2021

LE BRETON, David. Adeus ao corpo. 6. ed. Campinas: Papirus, 2013.

LOURO, Guacira Lopes. Gênero, sexualidade e educação: uma perspectiva pós estruturalista. Petrópolis: Vozes, 1997.

LUMIDOLLS. About us. 2019. Disponível em: < https://lumidolls.com/en/content/about-us >. Acesso em: 05 abr. 2021.

MACKENZIE, Robin. Sexbots: replacements for sex workers? Ethical constraints on the design of sentient beings for utilitarian purposes. In: Proceedings of the 2014 Workshops on Advances in Computer Entertainment Conference. ACM, 2014, s/p. Disponível em: < https://dl.acm.org/citation.cfm?id=2693789 >. Acesso em: 12 abr. 2021.

MARIJUÁN, Andrea Abalia. La rebelión de Galatea: autómatas, cíborgs y otras construcciones femeninas subversivas del siglo XXI. UMÁTICA. Revista sobre Creación y Análisis de la Imagen, n. 1, p. 33-56, 2018. Disponível em: < https://revistas.uma.es/index.php/ umatica/article/view/4743/5776 >. Acesso em: 27 abr. 2021. 
NACIONAL ABCIBER, 9. 2016. São Paulo. Cibercultura, democracia e liberdade no Brasil. 2019, s/n. Disponível em: < http://abciber.org.br/anaiseletronicos/wp-content/ uploads/2016/trabalhos/inteligencia_artificial_questoes_eticas_a_serem_enfrentadas_dora_kaufman.pdf >. Acesso em: 11 abr. 2021.

OLIVEIRA, José Antônio Colvara. Robótica como interface da tomada de consciência da ação e do conhecimento do objeto, através de metacognição como propulsora da produção do conhecimento. 2007. 96f. + Anexos. Tese (Doutorado) - Programa de Pós-graduação em Informática na Educação, Universidade Federal do Rio Grande do Sul, Porto Alegre, 2007. Disponível em: < https://www.lume.ufrgs.br/handle/10183/14662 >. Acesso em: 06 mai. 2021.

PANETTA, Kasey. CIO's can separate Al hype from reality by considering these areas of risk and opportunity, Smarter With Gartner, February 2019, s/p. Disponível em: < https://www.gartner.com/smarterwithgartner/the-cios-guide-to-artificial-intelligence/ >. Acesso em: 16 fev. 2021.

REALBOTIX, 2019. Disponível em: < https://realbotix.com/ >. Acesso em: 5 abr. 2021.

REALDOLL, 2019. Disponível em: < https://www.realdoll.com/product/harmony-x/ >. Acesso em: 05 abr. 2021.

REALDOLLx, 2019. Disponível em: < https://www.realdollx.ai/ >. Acesso em: 5 abr. 2021. ROBERTSON, Jennifer. Gendering Humanoid Robots: Robo-Sexism in Japan. Body \& Society, v. 16, n. 2, p. 1-36, 2010. Disponível em: < https://sgp1.digitaloceanspaces.com/ proletarian-library/upload-books/2018-05-08/Gendering\%20Humanoid\%20Robots.pdf >. Acesso em: 5 abr. 2021.

ROSADO, Maria José. O impacto do feminismo sobre o estudo das religiões. Cadernos Pagu, n. 16, p. 79-96, 2001. Disponível em: < https://www.scielo.br/scielo.php?pid=S0104$-83332001000100005 \&$ script=sci_arttext\&tlng=pt >. Acesso em: 28 mai. 2021.

ROSADO-NUNES, Maria José. Teologia Feminista e a crítica da razão religiosa patriarcal: entrevista com Ivone Gebara. Estudos Feministas, Florianopólis, v. 14, n. 1, p. 294-304. 2006. Disponível em < https://www.scielo.br/j/ref/a/ZZ7mhVDBZCMGLmnDMpBMhNS/ ?lang=pt >. Acesso em: 28 mai. 2021.

SCOTT, Joan Wallach. Prefácio a gender and politics of history. Cadernos Pagu, n. 3, p. 11-27, 1994. Disponível em: < https://bit.ly/2MKDtDB >. Acesso em: 15 fev. 2021.

SCOTT, Joan. Gênero: Uma categoria útil de análise histórica. Educação e Realidade, Porto Alegre, v. 16, n. 2, p. 5-22, jul./dez. 1990.

SIEGEL, Mikey; BREAZEAL, Cynthia; NORTON, Michael I. Persuasive robotics: the influence of robot gender on human behavior. In: Proceedings of Intelligent Robots and Systems, IEEE/RSJ International Conference, [S.I.]: IEEE, p. 2563-2568, 2009. Disponível em: < http://hdl.handle.net/1721.1/61618 >. Acesso em: 3 mai. 2021. 
SØRAA, Roger Andre. Mechanical genders: how do humans gender robots? Gender, Technology and development, v. 21, n. 1-2, p. 99-115, 2017. Disponível em: < https:// www.tandfonline.com/doi/full/10.1080/09718524.2017.1385320 >. Acesso em: 15 fev. 2021.

SOUZA, Sandra Duarte. Revista Mandrágora: Gênero e religião nos estudos feministas. Estudos feministas. Florianópolis, n. 12, p. 122-130, 2004. Disponível em: < http://www. scielo.br/pdf/ref/v12nspe/a14v12ns.pdf >. Acesso em: 28 mai. 2021.

STAMFORD, Conn. Gartner Identifies Five Emerging Technology Trends That Will Blur the Lines Between Human and Machine. Gartner, ago. 2018, n/p. Disponível em: < https://www.gartner.com/en/newsroom/press-releases/2018-08-20-gartner-identifies-five-emerging-technology-trends-that-will-blur-the-lines-between-human-and-machine >. Acesso em: 16 fev. 2021.

ULRICH, Claudete Beise. Relações de Gênero. In: IECLB. Relações de Gênero. São Leopoldo: Sinodal; Porto Alegre: IECLB, 2013.

XIN, Yang; KONG, Lingshuang; LIU, Zhi; et al. Machine learning and deep learning methods for cybersecurity. IEEE Access, v. 6, p. 35365-35381, 2018. Disponível em: < https:// ieeexplore.ieee.org/stamp/stamp.jsp?arnumber=8359287 >. Acesso em: 15 fev. 2021.

Submetido em: 22-4-2021

Aceito em: 25-5-2021 